\title{
ENRAIZAMENTO DE ESTACAS, CRESCIMENTO E RESPOSTAS ANATÔMICAS DE MUDAS CLONAIS DE CACAUEIRO AO ÁCIDO INDOL-3-BUTÍRICO ${ }^{1}$
}

\author{
ALBERTO JOSÉ DOS SANTOS JÚNIOR ${ }^{2}$,ALEX-ALAN FURTADO DEALMEIDA ${ }^{3 *}$, DELMIRADACOSTASILVA ${ }^{3}$, \\ JOSÉ CLÁUDIO FARIA ${ }^{4}$, MARCELO SCHRAMM MIELKE ${ }^{3}$,FÁBIO PINTO GOMES ${ }^{3}$
}

RESUMO: Avaliaram-se os efeitos do ácido indol-3-butírico (AIB) no crescimento e na morfologia interna de quatro clones de Theobroma cacao (CCN-10, CP-53, PS-1319 e CA-1.4). O AIB foi aplicado na base da estaca de caule, em talco inerte, nas concentrações de 2; 4; 6 e $8 \mathrm{~g} \mathrm{~kg}^{-1}$, juntamente com o controle (sem AIB). A avaliação do crescimento de raízes, caule e folhas dos quatro clones foi realizada aos 160 dias após o estaqueamento (DAE) para todas as concentrações de AIB, período também em que se realizou a coleta de material para os estudos anatômicos dos diversos órgãos, mas somente para a concentração de $4 \mathrm{~g} \mathrm{~kg}^{-1} \mathrm{AIB}^{\mathrm{a}} \mathrm{o}$ controle. O clone CA-1.4 apresentou incremento na biomassa seca de raiz (BSR) com o aumento das concentrações de AIB, ao passo que, nos demais clones, houve diminuições de BSR a partir dos $4 \mathrm{~g} \mathrm{~kg}^{-1} \mathrm{AIB}$. O mesmo fato foi observado para a biomassa seca de caule (BSC) e de folha (BSF), exceto para a BSC do CCN-10 que não respondeu ao incremento das concentrações de AIB. Houve aumento de área foliar total para os clones CP-53 e PS-1319 com o incremento de AIB até $4 \mathrm{~g} \mathrm{~kg}^{-1}$, enquanto o aumento do número de folhas ocorreu somente para os clones CA-1.4 e CP-53 até as concentraç̃oes 8 e $4 \mathrm{~g} \mathrm{~kg}^{-1} \mathrm{AIB}$, respectivamente. Houve diminuição do número de estacas mortas para os clones CA-1.4 e CCN-10 até $8 \mathrm{~g} \mathrm{~kg}^{-1}$ de AIB e para o CP-53 até $4 \mathrm{~g} \mathrm{~kg}^{-1}$ de AIB. As melhores concentrações de AIB para o enraizamento de estacas de ramos dos clones de cacaueiros CP-53, PS-1319 e CCN-10 foram de 4, 4 e $6 \mathrm{~g} \mathrm{~kg}^{-1} \mathrm{AIB}$, respectivamente, enquanto para o clone CA-1.4 foi de $8 \mathrm{~g} \mathrm{~kg}^{-1} \mathrm{AIB}$; o aumento da concentração de AIB promoveu mudanças anatômicas nos órgãos vegetativos de todos os clones, influenciando na atividade do câmbio vascular e induzindo a formação de um maior número de raízes adventícias nas estacas.

Termos de indexação: Theobroma cacao, propagação assexuada, produção de biomassa, regulador de crescimento.

\section{STEM CUTTING ROOTING, GROWTH AND ANATOMICAL RESPONSES OF CACAO TREE CLONAL CHANGES TO THE INDOLE-3-BUTYRIC ACID}

\begin{abstract}
The effects of indole-3-butyric acid (IBA) on growth and internal morphology of four clones of Theobroma cacao (CCN-10, CP-53, PS-1319 and CA-1.4) were evaluated. The IBA was applied in the base of stem cuttings, as an inert talc, in mixture concentrations of 2, 4, 6 and $8 \mathrm{~g} \mathrm{~kg}^{-1}$ together with the control, without IBA. The evaluation of the growth of roots, stem and leaves of the four clones were accomplished by 160 days after the cutting (DAC) for all the IBA concentrations. However, the anatomical studies of the several plant organs were also made to the $160 \mathrm{DAC}$, but only for the concentration of $4 \mathrm{~g} \mathrm{~kg}^{-1} \mathrm{IBA}$ and the control. The clone CA-1.4 presented increment in the root dry biomass (RDB) with the increase of the IBA concentrations, while for the other clones there were decreases of RDB starting from the $4 \mathrm{~g} \mathrm{~kg}^{-1}$ IBA. The same fact was observed for the stem and leaf dry biomass, except for $\mathrm{CCN}-10$ that did not answer to the increment of the concentrations of IBA. There was an increase of the total leaf area for the clones CP-53 e PS-1319 with the increment of the IBA (concentration up to $4 \mathrm{~g} \mathrm{~kg}^{-1}$ ), while the leaves number only increased for the clones CA-1.4 and CP-53, concentrations up to 8 and $4 \mathrm{~g} \mathrm{~kg}^{-1} \mathrm{IBA}$, respectively. There was a decrease in the number of dead cuttings for the clones CA-1.4 and CCN-10 (up $8 \mathrm{~g} \mathrm{~kg}^{-1}$ ) of IBA and for the CP-53 (up to $4 \mathrm{~g} \mathrm{~kg}^{-1}$ of IBA). The best IBA concentrations for the branch cutting rooting of the cacao clones CP-53, PS-1319 and CCN-10 were of 4,4 and $6 \mathrm{~g} \mathrm{~kg}^{-1}$ respectively, while for the clone CA1.4 was the one of $8 \mathrm{~g} \mathrm{~kg}^{-1}$; the increase of the IBA concentration promoted anatomical changes in the plant organs of all the clones, influencing the activity of the vascular cambium in the stem and inducing the formation of a larger number of adventitious roots in the stem cuttings.
\end{abstract}

Index terms: Theobroma cacao, asexual propagation, biomass production, growth regulator.

\footnotetext{
'(Trabalho 255-07). Recebido em: 26-10-2007. Aceito para publicação em: 04-11-2008. Parte da dissertação apresentada pelo primeiro autor para obtenção do grau de mestre em Produção Vegetal, Universidade Estadual de Santa Cruz (UESC).

${ }^{2}$ Mestre em Produção Vegetal pela UESC, km 16 da Rodovia Ilhéus-Itabuna, CEP 45662-000, Ilhéus-BA. E-mail: orqbio@yahoo.com.br.*Autor correspondente e Bolsista de Produtividade do CNPq.

${ }^{3}$ Professores do Departamento de Ciências Biológicas da UESC. E-mail: alexalan@uesc.br; delmira@uesc.br; msmielke@uesc.br; gomes@uesc.br. ${ }^{4}$ Professor do Departamento de Ciências Exatas e Tecnológicas da UESC. E-mail: jc_faria@uesc.br.
} 


\section{INTRODUÇÃO}

No Brasil, a maior área de produção de T. cacao encontrase na Bahia, onde praticamente 100 municípios têm sua economia baseada no cacau, cultivado em aproximadamente $29 \mathrm{mil}$ propriedades, em área de 559 mil ha. Nessa região, cultiva-se o $T$. cacao sob sombra de árvores da Mata Atlântica em sistema de 'Cabruca' ou com outras árvores de valor econômico (Almeida \& Valle, 2007). Com o surgimento da vassoura-de-bruxa (Moniliphthora perniciosa) na Bahia, em 1989, houve um decréscimo de mais de $60 \%$ na produção de amêndoas secas (Pereira et al., 1989). A partir dessa época, surgiu a preocupação com relação à proliferação de $M$. perniciosa nas lavouras dessa região e houve a necessidade de substituir os genótipos suscetíveis por plantas resistentes propagadas assexuadamente pelo método de estaquia, visto que a resistência genética das plantas é extremamente importante no controle da doença, principalmente em se tratando de uma espécie alógama.

Tradicionalmente, as plantas de $T$. cacao cultivadas na região tinham sua origem via seminal, em virtude de as plantas híbridas apresentarem melhores respostas em condições de campo e reduzidas taxas de segregação na geração F1 (Dias, 1993). Com a seleção de novos clones de T. cacao resistentes ao M. perniciosa, a propagação assexuada vem crescendo no Estado com produção de cerca de 6,6 milhões de mudas entre os meses de julho de 1999 e julho de 2004 ( Marrocos\& Sodré, 2004).

A partir de estudos realizados em condições de viveiro, com sistema de irrigação por microaspersão, testando concentrações crescentes de AIB ( Faria\& Sacramento, 2003) e tipos de estacas de caule (Sena-Gomes- et al., 2000), verificou-se que: (i) os índices de enraizamento para alguns clones de T. cacao foram superiores a $87 \%$, mesmo em estacas não-tratadas com AIB; (ii) o início da emissão das raízes adventícias ocorre entre 20 e 30 dias após o estaqueamento; (iii) o genótipo tem forte influência na taxa de sobrevivência das estacas, e (iv) as taxas médias de enraizamento para alguns clones são superiores a $70 \%$, ao passo que para outros são inferiores a $30 \%$. De acordo com Hartman et al. (1997), taxas de enraizamento para T. cacao inferiores a $50 \%$ não são economicamente viáveis para a produção comercial em larga escala. Logo, existem ainda controvérsias em relação aos fatores que afetam o enraizamento das estacas de caule de $T$. cacao, principalmente com relação ao uso de auxinas sintéticas

As auxinas sintéticas, quando em concentrações adequadas, têm sido muito úteis na indução da formação de raízes adventícias em estacas de caule durante a propagação assexuada de diversas espécies lenhosas (Sodré, 2007), sendo o AIB o mais utilizado ( Machado et. al., 2005) e o mais efetivo, por possuir comprovada atividade auxínica (Lopes et al., 2003) e estimular a síntese de etileno, que favorece a emissão de raízes (Norbertoet al., 2001). A facilidade proporcionada e o aumento do poder de comercialização são amplamente determinados pelas respostas das estacas ao enraizamento, definindo benefícios subseqüentes para o estabelecimento, rápido crescimento e uniformidade do lote (Davis \& Haissig, 1994).
As raízes adventícias podem surgir em nós associados às gemas ou em outras regiões. Nas estacas, o desenvolvimento do primórdio de raiz adventícia é estabelecido endogenamente, com origem histológica próxima ao sistema vascular, entretanto a exata origem depende da idade do caule e da espécie (Azamal et al., 2006).

O presente trabalho teve como objetivo principal avaliar o enraizamento das estacas de caule, o crescimento e as respostas anatômicas de quatro clones de T. cacao ao ácido indol-3-butírico (AIB).

\section{MATERIAL E MÉTODOS}

\section{Coleta, Preparo das Estacas e Estaqueamento}

Foram propagados assexuadamente os clones PS-1319, CP-53, CCN-10 e CA-1.4, de alta produção e tolerantes à doença vassoura-de-bruxa, a partir do enraizamento de estacas, obtidas de extremidades de ramos plagiotrópicos de plantas-matrizes com cinco a dez anos de idade, cultivadas nos jardins clonais do Instituto Biofábrica de Cacau (IBC), localizado no distrito do Banco do Pedro, Ilhéus-BA.

A coleta das extremidades dos ramos dos diversos clones, com aproximadamente $30 \mathrm{~cm}$ de comprimento,foi realizada no período da manhã, entre 7 e $8 \mathrm{~h}$. Em seguida, os ramos foram transportados do campo, em carro fechado, para as instalações do IBC, onde foram constantemente umedecidos com água, por meio de microaspersão, até o momento do preparo das estacas.

O preparo das estacas ocorreu entre 9 e $11 \mathrm{~h}$ do mesmo dia, sendo o comprimento dos ramos reduzido para $16 \mathrm{~cm}$ a partir do ápice, permanecendo, além da gema apical e das folhas jovens, com quatro gemas axilares e quatro folhas maduras, cuja área individual foi reduzida a 1/4. Logo após, cerca de $3 \mathrm{~cm}$ da porção basal foi imergida em água e, em seguida, imersa em talco inerte contendo diferentes concentrações de AIB (2; 4; 6 e 8 g $\left.\mathrm{kg}^{-1}\right)$. Posteriormente, procedeu-se ao estaqueamento em tubetes de polietileno pretos com capacidade de $288 \mathrm{~cm}^{3}$, contendo substrato orgânico (casca de Pinnus + fibra de coco na proporção de 1:1) enriquecidos com macro e micronutrientes minerais de acordo com as exigências da cultura, e colocados em bandejas plásticas com capacidade para 54 tubetes. Em seguida, as bandejas foram transportadas para viveiro coberto com telas de plástico preto com $50 \%$ de sombra e com sistema de irrigação por microaspersão, onde permaneceram por 160 dias.

No viveiro, nos primeiros 60 dias após o estaqueamento, período necessário para a formação das raízes adventícias, o sistema de irrigação foi acionado automaticamente, com o uso de um timer, a cada cinco minutos, por um período de aspersão de trinta segundos, totalizando uma vazão de $40 \mathrm{~L} \mathrm{~h}^{-1}$, proporcionando ao ambiente uma umidade relativa do ar próxima de $100 \%$. Após esse período, alterou-se o sistema de aspersão para intervalos de dez minutos, com aspersão por trinta segundos, perfazendo um total de $20 \mathrm{~L} \mathrm{~h}^{-1}$, que permaneceu até o final do experimento. 


\section{Obtenção das Variáveis de Crescimento}

Decorridos 160 dias após o estaqueamento (DAE), as mudas clonais de $T$. cacao foram retiradas do substrato efetuando-se, então, a divisão das mesmas em raízes, caule e folhas. Imediatamente após, mensurou-se a área foliar, utilizandose um medidor portátil de área foliar modelo Li-3100 (Li-Cor, Nebraska, USA), e as diversas partes das mudas clonais foram acondicionadas em sacos de papel e, em seguida, colocadas para secar em estufa de circulação forçada de ar, a $75^{\circ} \mathrm{C}$, até massa constante, para obtenção de biomassa seca.

\section{Estudos Anatômicos}

Os estudos anatômicos foram realizados somente para as estacas tratadas com a concentração de $4 \mathrm{~g} \mathrm{~kg}^{-1} \mathrm{AIB}$ e as do tratamento-controle, em virtude de ser uma concentração comumente usada dessa auxina sintética para a propagação assexuada da maioria das espécies lenhosas. Para esses estudos, foram coletadas amostras de raízes, caules e folhas dos diferentes clones avaliados aos $160 \mathrm{DAE}$, as quais foram fixadas em FAA a $70 \%$ (Johansen, 1940) e conservadas em etanol a $70 \%$. Posteriormente, as amostras foram incluídas em parafina e seccionadas em micrótono de deslize Leitz modelo 1208. Em seguida, os cortes foram corados com safranina a $2 \%$ e azul de astra a 1\% (Kraus \& Arduin, 1997). Para a documentação dos resultados, foram obtidas fotomicrografias em fotomicroscópio Olympus, modelo Bx 50 .

\section{Análise Estatística}

Adotou-se delineamento experimental inteiramente ao acaso, esquema fatorial 4 (clones) x 5 (concentração de AIB), com quatro repetições. Cada parcela foi representada por 27 estacas, das quais foram coletadas 10 estacas para avaliação da biomassa seca de raízes, caule e folhas, medição de área foliar e contagem do número de folhas. Para a contagem do número de estacas mortas (NEM), considerou-se o número total de estacas da parcela. Os dados obtidos foram submetidos inicialmente à análise de variância, usando o programa estatístico R (http:// www.R.project.org), e, posteriormente, às análises de regressão para as variáveis de crescimento (Tabela 1).

\section{RESULTADOS E DISCUSSÃO}

Concentrações crescentes de AIB reduziram o número de estacas mortas (NEM) para os clones CA-1.4 e CCN-10, enquanto para o clone CP-53 essa redução ocorreu até a concentração de $4 \mathrm{~g} \mathrm{~kg}^{-1}$, que, logo após, foi seguida de aumento, ao passo que, para o clone PS-1319, permaneceu relativamente constante (Figura 1). Elevada sobrevivência também foi obtida por Faria \& Sacramento (2003) para estacas do clone TSH 1188 de T. cacao tratadas com $6 \mathrm{~g} \mathrm{~kg}^{-1}$ de AIB e cultivadas nas mesmas condições. Bastos et al. (2005), ao avaliarem o índice de sobrevivências das estacas de carambola (Averrhoa carambola), tratadas com 2; 4 e $6 \mathrm{~g} \mathrm{~L}^{-1}$ de AIB, observaram que os maiores índices foram obtidos para as estacas herbáceas tratadas com $6 \mathrm{~g} \mathrm{~L}^{-1}$ de AIB. Por outro lado, Sodré (2007), trabalhando com miniestacas de T. cacao, tratadas com $6 \mathrm{~g} \mathrm{~kg}^{-1}$ de AIB em câmara de nebulização com controle do ambiente (água, luz e temperatura), verificou que os valores encontrados para a porcentagem de sobrevivência de estacas não diferiram estatisticamente entre os tratamentos com diferentes substratos e clones.

Segundo Lima et al. (2006), a formação de novas estruturas na parte aérea das estacas funciona como dreno metabólico, que consome as reservas de carboidratos e de compostos nitrogenados das estacas, podendo conduzi-las à morte; principalmente se o surgimento dessas estruturas antecederem a emissão das raízes adventícias na parte basal das estacas. Por outro lado, clones de T. cacao que apresentam percentuais elevados de sobrevivência em experimentos bem controlados, podem não repetir os mesmos resultados em larga escala, sendo esse um fator negativo no processo de multiplicação (Sodré, 2007).

A capacidade de enraizamento das estacas de ramo e a qualidade das mudas enraizadas de T. cacao variam com: (i) a época do ano em que as estacas foram coletadas (Leite, 2006); (ii) a posição da estaca no ramo (apical e subapical) (Sena-Gomes et al., 2000); (iii) o tipo de ramo (ortotrópico ou plagiotrópico) (Miller \& Guiltinan, 2003); (iv) o comprimento da estaca (Guiltinan et al., 2000); (v) o número e o tamanho das folhas remanescentes na estaca (Leite, 2006); (vi) a concentração de reguladores de crescimento (Leite 2006); (vii) o tipo e a composição química do substrato (Sodré, 2007); (viii) o teor de umidade do substrato (Bertolde, 2007); (ix) a nutrição mineral e a sanidade das plantas matrizes, $\mathrm{e}(\mathrm{x})$ a variabilidade genética das plantas-matrizes (SenaGomes et al., 2000).

No presente estudo, para todos os clones avaliados, o tempo decorrido entre a coleta de extremidades de ramos plagiotrópicos de plantas-matrizes no campo e o estaqueameto no IBC foi de aproximadamente $4 \mathrm{~h}$. De acordo com Sodré (2007), o sucesso do enraizamento das miniestacas de $T$. cacao tratadas com $6 \mathrm{~g} \mathrm{~kg}^{-1}$ de AIB deveu-se ao curto espaço de tempo decorrido entre o corte da miniestaca e o estaqueamento, o qual foi sempre inferior a 20 minutos. Estudos realizados por Wendling et al. (2000), com miniestacas de eucalipto (Eucaliptus grandis) tratadas com AIB, demonstraram que atrasos decorridos entre $\mathrm{o}$ corte do ramo na planta-matriz e o estaqueamento diminuíram a turgescência e aumentaram a oxidação da base de miniestacas, reduzindo o percentual de enraizamento.

Os clones CCN-10 e CA-1.4 apresentaram incremento de biomassa seca de raiz (BSR) com o aumento das concentrações de AIB até 6 e $8 \mathrm{~g} \mathrm{~kg}^{-1}$, respectivamente, enquanto para os demais clones o acréscimo de BSR ocorreu até $4 \mathrm{~g} \mathrm{~kg}^{-1} \mathrm{de}$ AIB (Figura 2). O mesmo fato foi observado para a biomassa seca de folha (BSF) (Figura 4). Por outro lado, para os clones CA-1.4, CP-53 e PS1319, o aumento da biomassa seca de caule (BSC) ocorreu até 8; $4 \mathrm{e} 4 \mathrm{~g} \mathrm{~kg}^{-1}$ de AIB, respectivamente, ao passo que, para o clone CCN-10, não houve resposta de BSC ao incremento de AIB (Figura 3). As diferenças interclonais em relação ao acúmulo de biomassa seca, nos diferentes órgãos vegetativos, em resposta às concentrações de $\mathrm{AIB}$, devem-se, em grande parte, à variabilidade genotípica de T. cacao (Sena-Gomes et al., 2000). $\mathrm{O}$ mesmo fato tem sido observado para diferentes espécies da 
família Mirtaceae, com o uso de concentrações crescentes de AIB variando de 1 a $5 \mathrm{~g} \mathrm{~kg}^{-1}$ (Coutinho et al., 1991).

Manfroi et al. (1997) observaram que o AIB promoveu o aumento de BSR e da biomassa seca das brotações em estacas de kiwi (Actinidia deliciosa). Resultados semelhantes foram obtidos por LOPES et al. (2003), durante o enraizamento de acerola (Malpighia emarginata), cujo incremento em BSR ocorreu até 2 $\mathrm{g} \mathrm{L}^{-1}$ de AIB, e por Iritani et al. (1986) durante o enraizamento de erva-mate (Ilex paraguariensis), variando as concentrações de AIB de 3 a $5 \mathrm{~g} \mathrm{~kg}^{-1}$. Norberto et al. (2001), tratando a base das estacas de figo (Fícus carica) com $1 \mathrm{~g} \mathrm{~L}^{-1}$ de AIB, encontraram diferenças significativas em BSR e verificaram que o incremento médio em todas as épocas avaliadas foi bem superior ao controle, ao passo que, para BSC, embora tenha havido incremento com o aumento das concentrações de AIB, houve tendência de decréscimo no decorrer da época da estaquia. Por outro lado, Bastos et al. (2005), usando 2; 4 e $6 \mathrm{~g} \mathrm{~L}^{-1}$ de AIB em estacas de carambola, verificaram que o maior acúmulo de BSR foi encontrado nas estacas herbáceas tratadas com $2 \mathrm{~g} \mathrm{~L}^{-1}$ de AIB e nas estacas-controle (sem AIB). Segundo Leakey \& Coutts (1989), em alguns casos, o aumento da biomassa seca das mudas clonais pode estar relacionado com a maior capacidade de enraizamento. Isso foi verificado no presente trabalho para o clone CA-1.4 que apresentou maior índice de enraizamento e maior incremento de BSC em relação aos demais clones (Figura 2)

Houve aumento de área foliar total (AF) para os clones CP-53 e PS-1319 com o incremento da concentração de AIB até a concentração de $4 \mathrm{~g} \mathrm{~kg}^{-1}$ de AIB, enquanto para os dois outros clones não houve resposta de $\mathrm{AF}$ ao incremento da concentração de AIB (Figura 5). Em contrapartida, observou-se aumento do número de folhas (NF) para os clones CA-1.4 e CP-53, com o incremento da concentração de AIB até 8 e $4 \mathrm{~g} \mathrm{~kg}^{-1}$, respectivamente, ao passo que, para o clone PS-1319, houve decréscimo de NF com o incremento das concentrações de AIB. Já para o clone $\mathrm{CCN}-10$, não se verificaram respostas de NF em relação ao aumento das concentrações de AIB (Figura 6).

A presença das folhas em estacas de caule e o sucesso do enraizamento têm sido demonstrados por diversos autores para várias espécies lenhosas (Leite, 2006). No caso do kiwi, a remoção de folhas promove uma redução drástica na formação de raízes (Lawes \& Sim, 1980). Segundo Hartmann et al. (1997), as gemas e folhas são fontes de auxinas, carboidratos e cofatores de enraizamento, sem os quais não ocorre o processo de formação de raízes. Além disso, as folhas estimulam a atividade cambial, diferenciação do xilema e iniciação das raízes (Lionakis, 1984) e favorecem a emissão de raízes pela absorção de água, evitando que haja desidratação das estacas (Nachtigal, 1994).

Estudos realizados por Wendling \& Xavier (2005), com estacas de plátano (Platanus acerifolia) de diferentes diâmetros, demonstraram que o AIB na concentração $6 \mathrm{~g} \mathrm{~kg}^{-1}$ aumentou significativamente o número de folhas, independentemente do diâmetro das estacas. Segundo esses autores, a quantidade de folhas formadas por estaca influenciou significativamente no processo de enraizamento, pois a emissão foliar favoreceu a sobrevivência das estacas e a emissão de raízes adventícias. Por outro lado, Lopes et al. (2003) demonstraram, usando concentrações crescente de AIB $\left(0,5 ; 1 ; 1,5\right.$ e $\left.2 \mathrm{~g} \mathrm{~L}^{-1}\right)$ em estacas de acerola, que o comprimento das raízes adventícias determinou o aumento na biomassa fresca e seca de raízes, e atribuíram esse aumento ao tipo de substrato utilizado e à presença das folhas nas estacas. Esse fato foi também observado para os clones CA1.4 e CCN-10, cujo incremento de BSR e AF foi proporcional às concentrações crescentes de AIB.

No estudo anatômico das raízes dos clones avaliados, foi observada maior quantidade de células lignificadas na concentração $4 \mathrm{~g} \mathrm{~kg}^{-1}$ AIB em relação ao controle, com exceção do clone CP-53, que apresentou, juntamente com o controle, menor desenvolvimento da estrutura secundária (Figuras 7 A H). Oliveira et al. (2003), comparando o enraizamento de estacas lenhosas e semilenhosas de pessegueiro (Prunus persica), utilizando AIB nas concentrações de 1,5 e 3,0 $\mathrm{g} \mathrm{L}^{-1}$, constataram que, em geral, as estacas semilenhosas apresentaram maior percentual de enraizamento em relação às lenhosas, atribuindo esse fato ao menor grau de lignificação nas semilenhosas e à presença das folhas. Nesse processo, as folhas têm papel importante, auxiliando no transporte de substâncias promotoras de enraizamento e promovendo a perda de água por transpiração (Costa Junior et al., 2003). Esse órgão, quando presente, proporciona efeitos significativos na interação com o AIB e na percentagem de enraizamento da estaca, como constatado por Gontijo et al. (2003) para estacas de aceroleira.

A presença de uma barreira mecânica causada pela disposição de esclerênquima é freqüentemente relatada na literatura (Mayer et al., 2006) como um dos principais empecilhos à formação de raízes adventícias em estaca. Entretanto, é importante considerar que tal disposição e a presença desse tecido não são características comuns a todas as espécies. Em $T$. cacao, a presença desse cilindro contínuo de fibras é ausente, e o que se observou foi a presença de fibras associadas, apenas na região do floema, formando faixas alternadas de fibras entre esse tecido, possivelmente de origem floemática. Observou-se, na região cambial, a presença de ampla faixa de células derivadas que se mantiveram uniformes tanto na presença quanto na ausência de AIB para os quatro clones de T. cacao avaliados (Figuras $8 \mathrm{C} \mathrm{e} \mathrm{G,} \mathrm{E} \mathrm{e} \mathrm{I,} \mathrm{Ae} \mathrm{F).} \mathrm{Essa} \mathrm{região,} \mathrm{porém,} \mathrm{mostrou-se} \mathrm{mais}$ estreita para o clone $\mathrm{CCN}-10$ na concentração $4 \mathrm{~g} \mathrm{~kg}^{-1} \mathrm{AIB}$, quando comparado ao controle (Figuras $8 \mathrm{D}$ e $\mathrm{H}$ ). $\mathrm{O}$ incremento da atividade meristemática do câmbio vascular induzida pela ação do AIB, formando zonas de proliferação que alternam entre si, tem sido relatado em estacas de Malpighia emarginata tratadas com de $5 \mathrm{~g} \mathrm{~kg}^{-1}$ AIB (Laskowski \& Bautista, 1999). Segundo Schwarz et al.(1999), a auxina induz a atividade meristemática, bem como a proliferação do câmbio vascular e o desenvolvimento do calo cortical precedendo o início do desenvolvimento das raízes.

Perceberam-se, na folha dos clones avaliados, diferentes respostas aos tratamentos em relação à distribuição do tecido clorofiliano. Nos clones PS-1319 e CA 1.4, observou-se o aumento do espaço intercelular na região do parênquima clorofiliano lacunoso (Figuras 9 C, G, D e H), mais reduzido nos clones PS1319 e CCN-10 (Figuras 9 A, E, B e F) em comparação aos demais 
e ao tratamento-controle. Ainda para o clone CA 1.4, notou-se a redução do espessamento do mesofilo, aspecto também observado para o clone CCN 10 que, juntamente com o Clone CP 53, apresentou mesofilo compactado com redução dos espaços intercelulares na região do parênquima lacunoso, quando comparado ao controle e aos demais clones (Figura 9 C, G, D e H). $\mathrm{O}$ aumento dos espaços intercelulares ocorre em detrimento da síntese de etileno, que pode estar associada ao aumento da
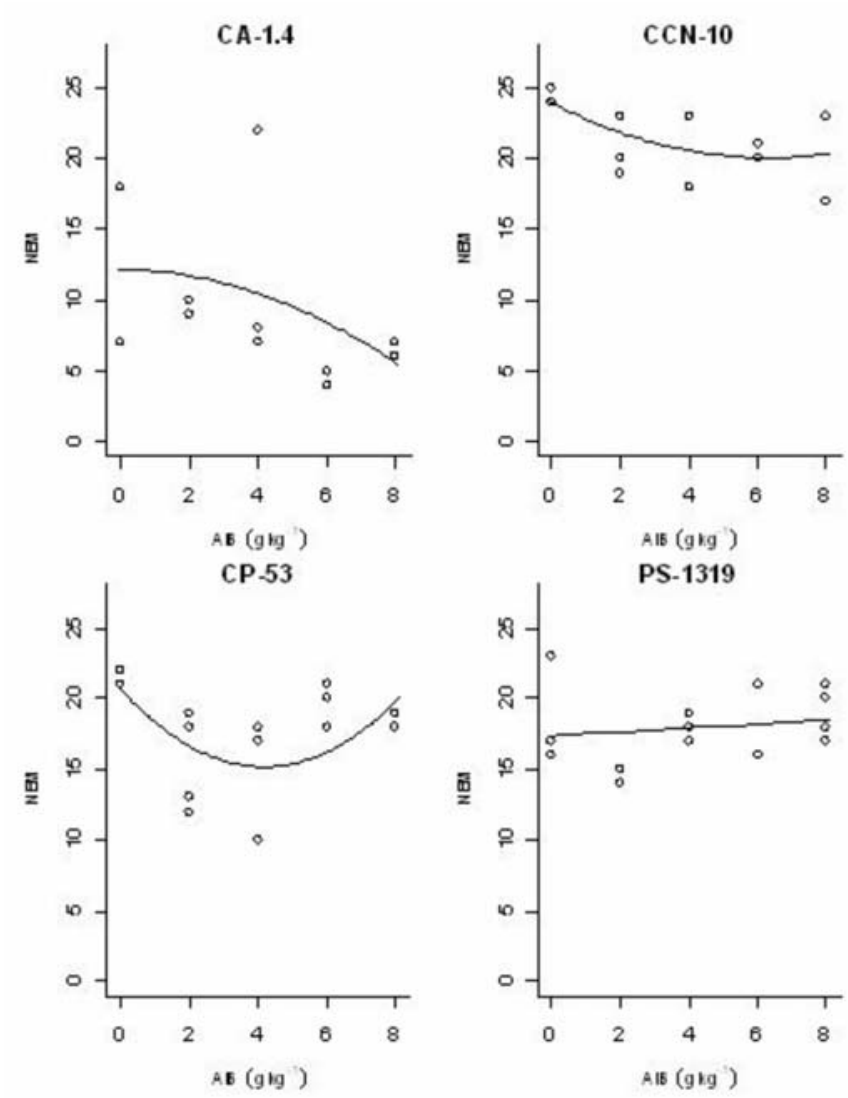

FIGURA 1 - Número de estacas mortas (NEM) dos quatro clones de T. cacao, obtidas a partir das estacas de caule e submetidas a concentrações crescentes de ácido indol-3-butírico (AIB). Cada ponto representa o valor médio de dez estacas, aos 160 dias após o estaqueamento. concentração de auxina que estimula a produção desse hormônio essencial ao processo de enraizamento, o qual pode induzir à formação de canais de ar (Taiz \& Zeiger, 2004). Tal aspecto pode estar relacionado à anatomia foliar dos clones estudados, que apresentaram espaços intercelulares mais amplos à medida que houve um incremento das doses de AIB.
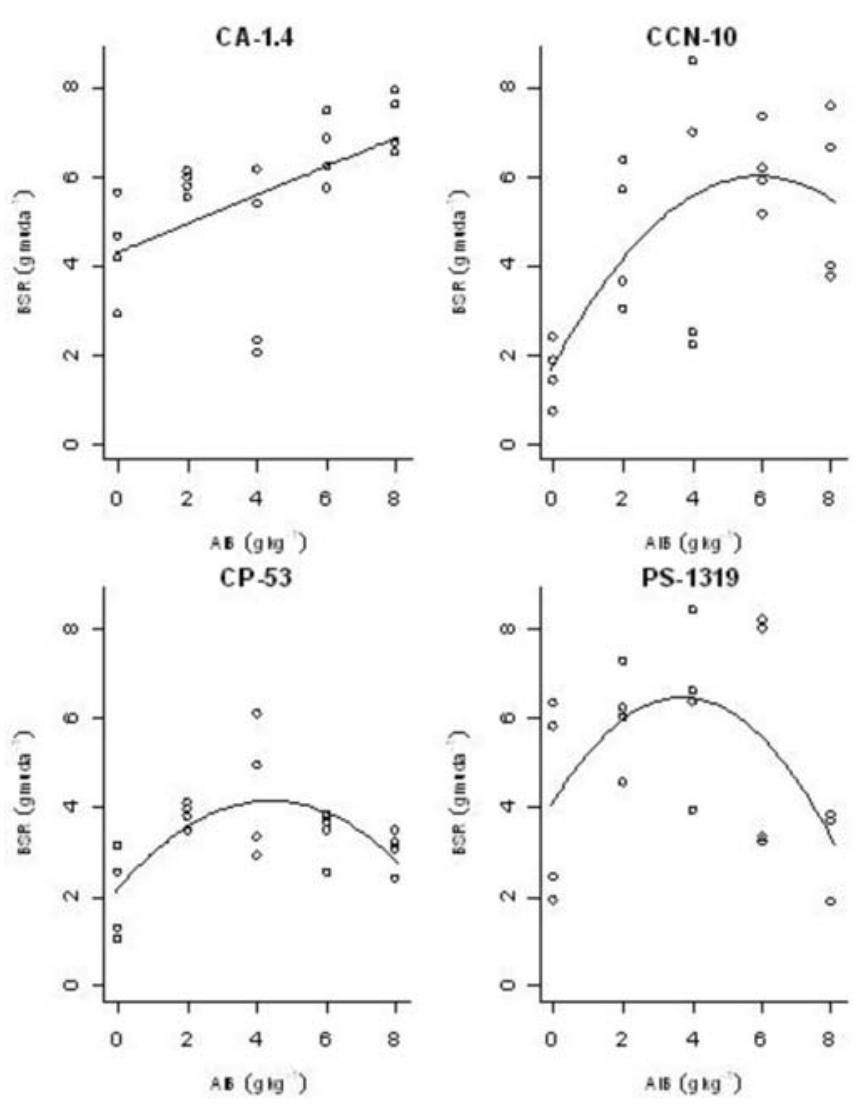

FIGURA 2 - Biomassa seca da raiz (BSR) de mudas dos quatro clones de T. cacao obtidas a partir das estacas de caule e submetidas a concentrações crescentes de ácido indol-3-butírico (AIB). Cada ponto representa o valor médio de dez mudas, aos 160 dias após o estaqueamento. 

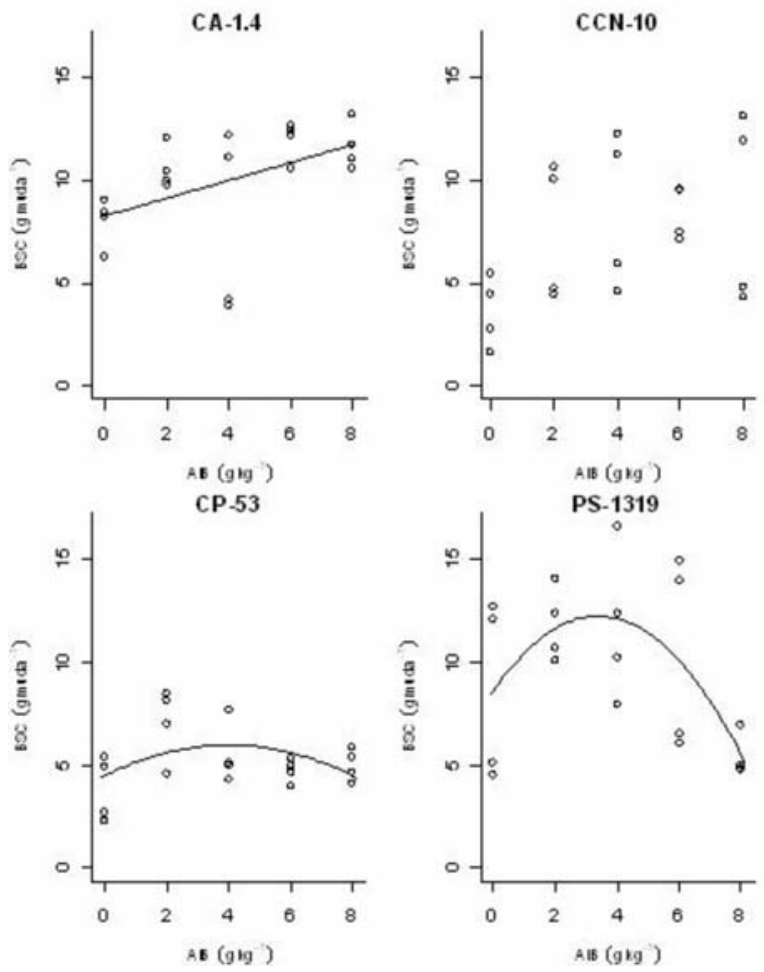

FIGURA 3 - Biomassa seca do caule (BSC) de mudas dos quatro clones de T. cacao obtidas a partir das estacas de caule e submetidas a concentrações crescentes de ácido indol-3-butírico (AIB). Cada ponto representa o valor médio de dez mudas, aos 160 dias após o estaqueamento.
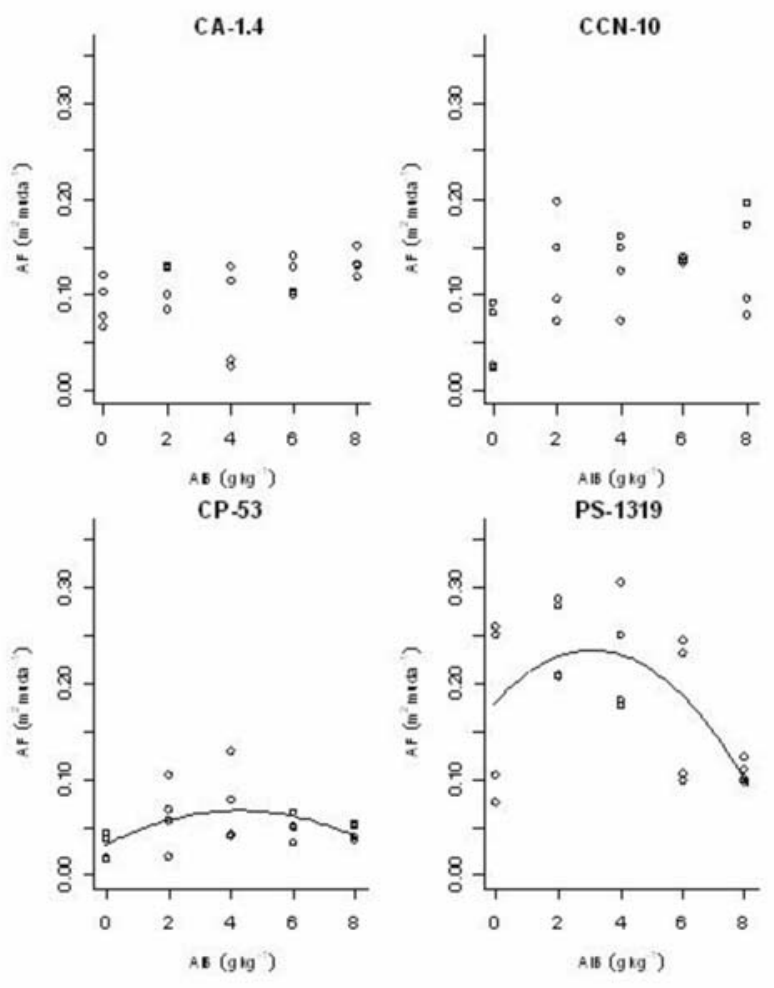

FIGURA 5 - Área foliar (AF) de mudas dos quatro clones de T. cacao obtidas a partir das estacas de caule e submetidas a concentrações

crescentes de ácido indol-3-butírico (AIB). Cada ponto representa o valor médio de dez mudas, aos 160 dias após o estaqueamento.
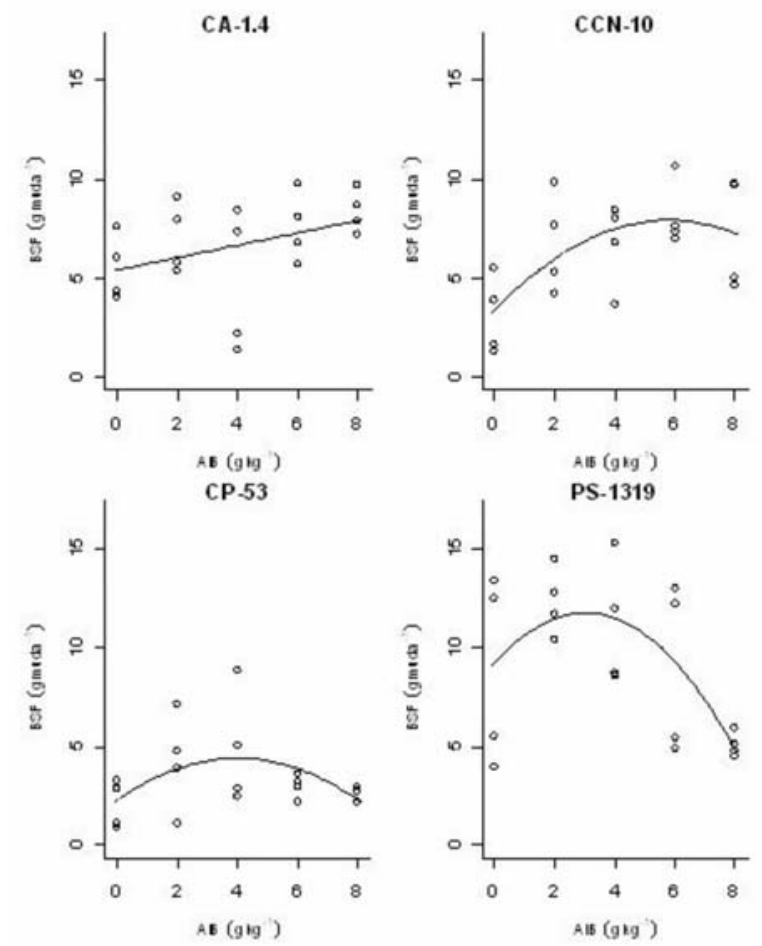

FIGURA 4 - Biomassa seca das folhas (BSF) de mudas dos quatro clones de T. cacao obtidas a partir das estacas de caule e submetidas a concentrações crescentes de ácido indol-3-butírico (AIB). Cada ponto representa o valor médio de dez mudas, aos 160 dias após o estaqueamento. Rev. Bras. Frutic., Jaboticabal - SP, v. 30, n. 4, p. 1071-1082, Dezembro 2008 

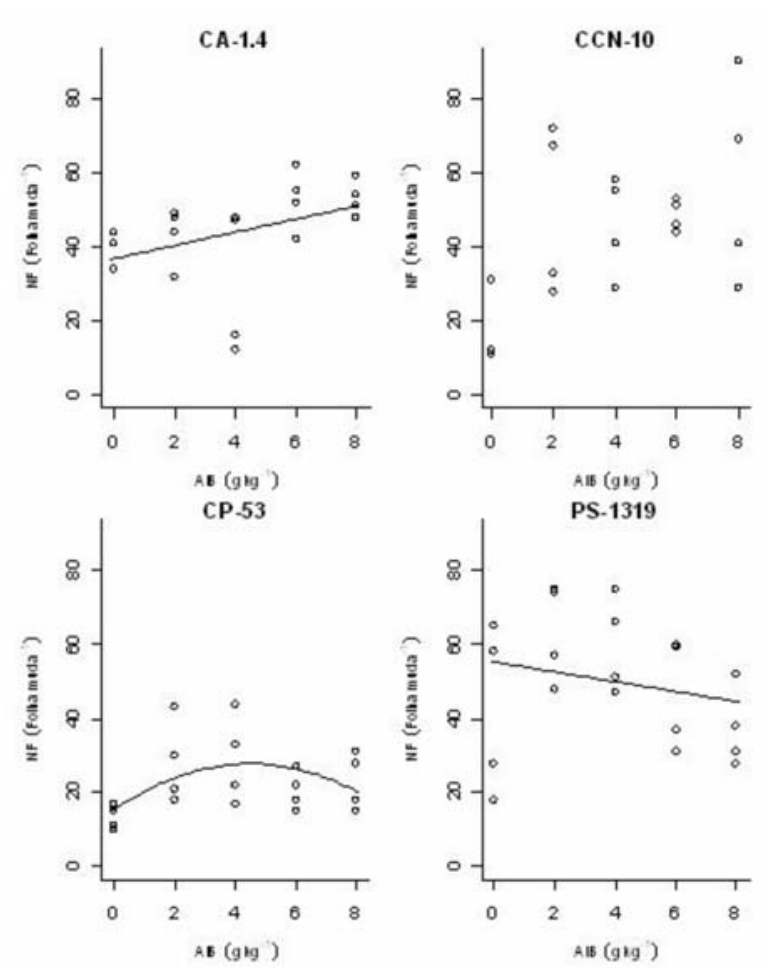

FIGURA 6 - Número de folhas (NF) de mudas dos quatro clones de T. cacao obtidas a partir das estacas de caule e submetidas a concentrações crescentes de ácido indol-3-butírico (AIB). Cada ponto representa o valor médio de dez mudas, aos 160 dias após o estaqueamento.

TABELA 1 - Variáveis de resposta, clones, equações de regressão e respectivos coeficientes de determinação. NEM = número de estacas mortas; BSR = biomassa seca de raízes (g); BSC = biomassa seca do caule (g); BSF = biomassa seca de folhas $(\mathrm{g}) ; \mathrm{AF}=$ área foliar $\left(\mathrm{m}^{2}\right) ; \mathrm{NF}=$ número de folhas.

\begin{tabular}{|c|c|c|c|c|}
\hline Variável de resposta & Clone & \multicolumn{2}{|c|}{ Equações de regressão } & $\mathbf{r}^{2}, \%$ \\
\hline \multirow{4}{*}{ NEM } & CA-1.4 & $\hat{\mathrm{Y}}$ & $-1,11250^{\mathrm{ns}} \mathrm{AIB}+0,15625^{*} \mathrm{AIB}^{2}$ & 33,97 \\
\hline & $\mathrm{CCN}-10$ & $\hat{\mathrm{Y}}$ & $-2,11071^{* * *} \mathrm{AIB}+0,16071^{*} \mathrm{AIB}^{2}$ & 93,32 \\
\hline & $\mathrm{CP}-53$ & $\hat{\mathrm{Y}}$ & $-2,64821^{\text {ns }} \mathrm{AIB}+0,31696^{* * *} \mathrm{AIB}^{2}$ & 60,67 \\
\hline & PS-1319 & $\hat{\mathrm{Y}}$ & $-0,45000^{* *} \mathrm{AIB}$ & 71,52 \\
\hline \multirow{4}{*}{ BSR } & CA-1.4 & $\hat{\mathrm{Y}}$ & ${ }^{* * *}$ AIB & 90,62 \\
\hline & $\mathrm{CCN}-10$ & $\hat{\mathrm{Y}}$ & ${ }^{* * *} \mathrm{AIB}-0,12133^{* * *} \mathrm{AIB}^{2}$ & 95,43 \\
\hline & CP-53 & $\hat{\mathrm{Y}}$ & ${ }^{\mathrm{ns}} \mathrm{AIB}-0,10276^{* *} \mathrm{AIB}^{2}$ & 85,30 \\
\hline & PS-1319 & $\hat{Y}$ & ${ }^{\mathrm{ns}} \mathrm{AIB}-0,17116^{* * *} \mathrm{AIB}^{2}$ & 99,52 \\
\hline \multirow{4}{*}{ BSC } & CA-1.4 & $\hat{\mathrm{Y}}$ & ${ }^{* *} \mathrm{AIB}$ & 70,33 \\
\hline & $\mathrm{CCN}-10$ & $\hat{Y}$ & & \\
\hline & CP-53 & $\hat{\mathrm{Y}}$ & ${ }^{* * *} \mathrm{AIB}-0,15449^{*} \mathrm{AIB}^{2}$ & 94,84 \\
\hline & PS-1319 & $\hat{\mathrm{Y}}$ & ${ }^{*} \mathrm{AIB}-0,31627^{* * *} \mathrm{AIB}^{2}$ & 99,18 \\
\hline \multirow{4}{*}{ BSF } & CA-1.4 & $\hat{\hat{Y}}$ & "AIB & 80,17 \\
\hline & $\mathrm{CCN}-10$ & $\hat{\mathrm{Y}}$ & $6^{* * * *} \mathrm{AIB}-0,13648^{*} \mathrm{AIB}^{2}$ & 91,11 \\
\hline & CP-53 & $\hat{\mathrm{Y}}$ & ${ }^{\mathrm{ns}} \mathrm{AIB}-0,13199^{*} \mathrm{AIB}^{2}$ & 75,63 \\
\hline & PS-1319 & $\hat{\mathrm{Y}}$ & ${ }^{* * *} \mathrm{AIB}-0,27933^{* * *} \mathrm{AIB}^{2}$ & 96,00 \\
\hline \multirow{4}{*}{$\mathrm{AF}$} & CA-1.4 & $\hat{\mathrm{Y}}$ & & \\
\hline & $\mathrm{CCN}-10$ & $\hat{\mathrm{Y}}$ & & \\
\hline & CP-53 & $\hat{\mathrm{Y}}$ & ${ }^{* *} \mathrm{AIB}-0,00245^{*} \mathrm{AIB}^{2}$ & 87,67 \\
\hline & PS-1319 & $\hat{\mathrm{Y}}$ & $0,181+0,03462^{* * *} \mathrm{AIB}-0,00561^{* * *} \mathrm{AIB}^{2}$ & 93,73 \\
\hline \multirow{4}{*}{$\mathrm{NF}$} & CA-1.4 & $\hat{\mathrm{Y}}$ & "AIB & 95,53 \\
\hline & $\mathrm{CCN}-10$ & $\hat{\mathrm{Y}}$ & & \\
\hline & CP-53 & $\hat{\mathrm{Y}}$ & ${ }^{\mathrm{ns}} \mathrm{AIB}-1,26339^{* * *} \mathrm{AIB}^{2}$ & 84,06 \\
\hline & PS-1319 & $\hat{\mathrm{Y}}$ & $-3,52500^{* * * *} \mathrm{AIB}$ & 66,19 \\
\hline
\end{tabular}

ns $,{ }^{0},{ }^{*},{ }^{* *},{ }^{* * *}$ : Não significativo, significativo a $15 ; 10 ; 5$ e $1 \%$ de probabilidade, respectivamente, pelo teste t.

Rev. Bras. Frutic., Jaboticabal - SP, v. 30, n. 4, p. 1071-1082, Dezembro 2008 


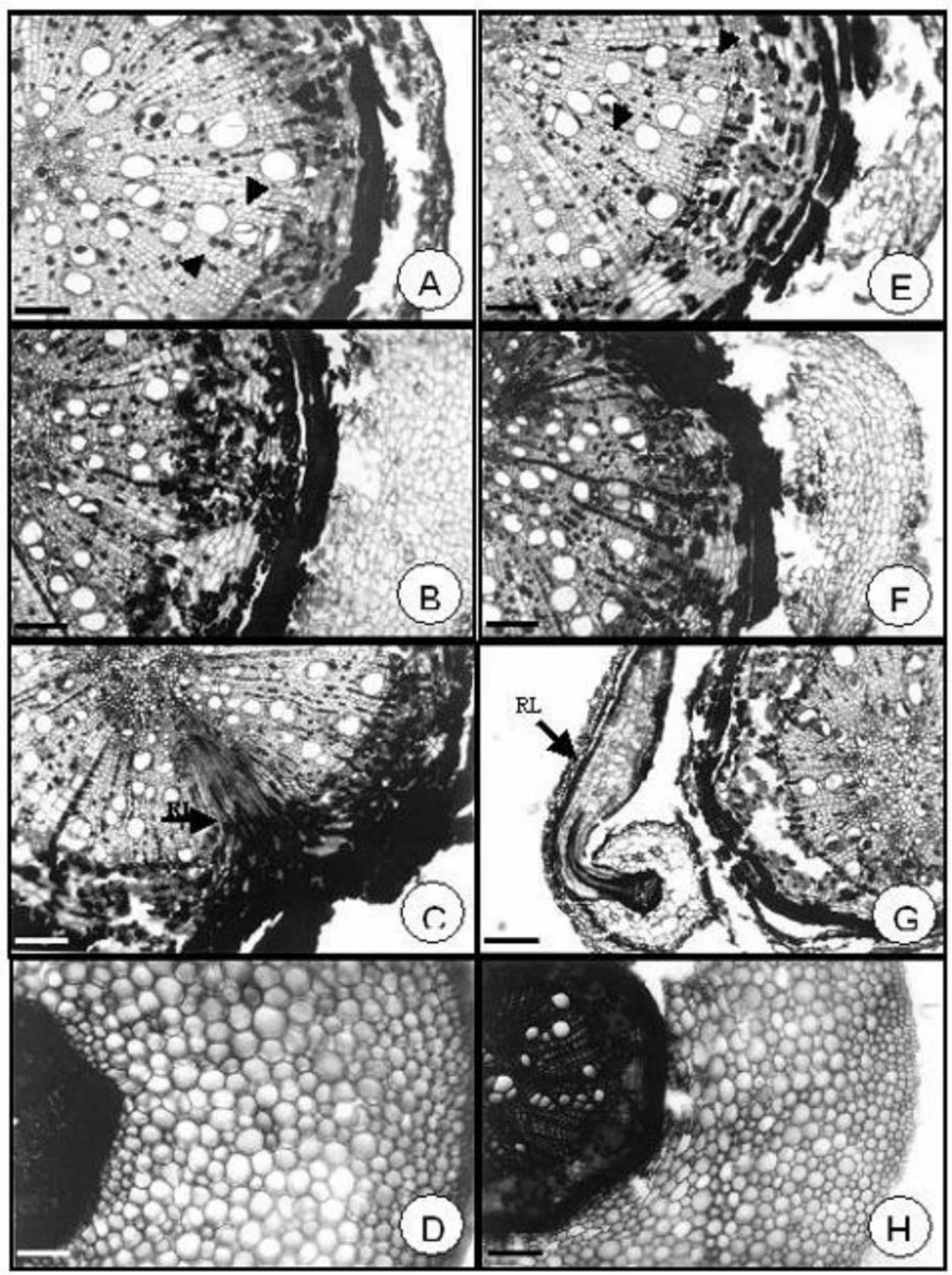

FIGURA 7 - Secção transversal da raiz de T. cacao dos clones PS-1319, CA-1.4, CCN-10 e CP-53, A, B, C e D, respectivamente, para o controle e E, F, G e H para o tratamento $4 \mathrm{~g} \mathrm{~kg}^{-1}$ de AIB, 160 dias após a aplicação de ácido indol-3-butírico (AIB). As setas indicam as regiões lignificadas. Barra $=30 \mu \mathrm{m}$. 


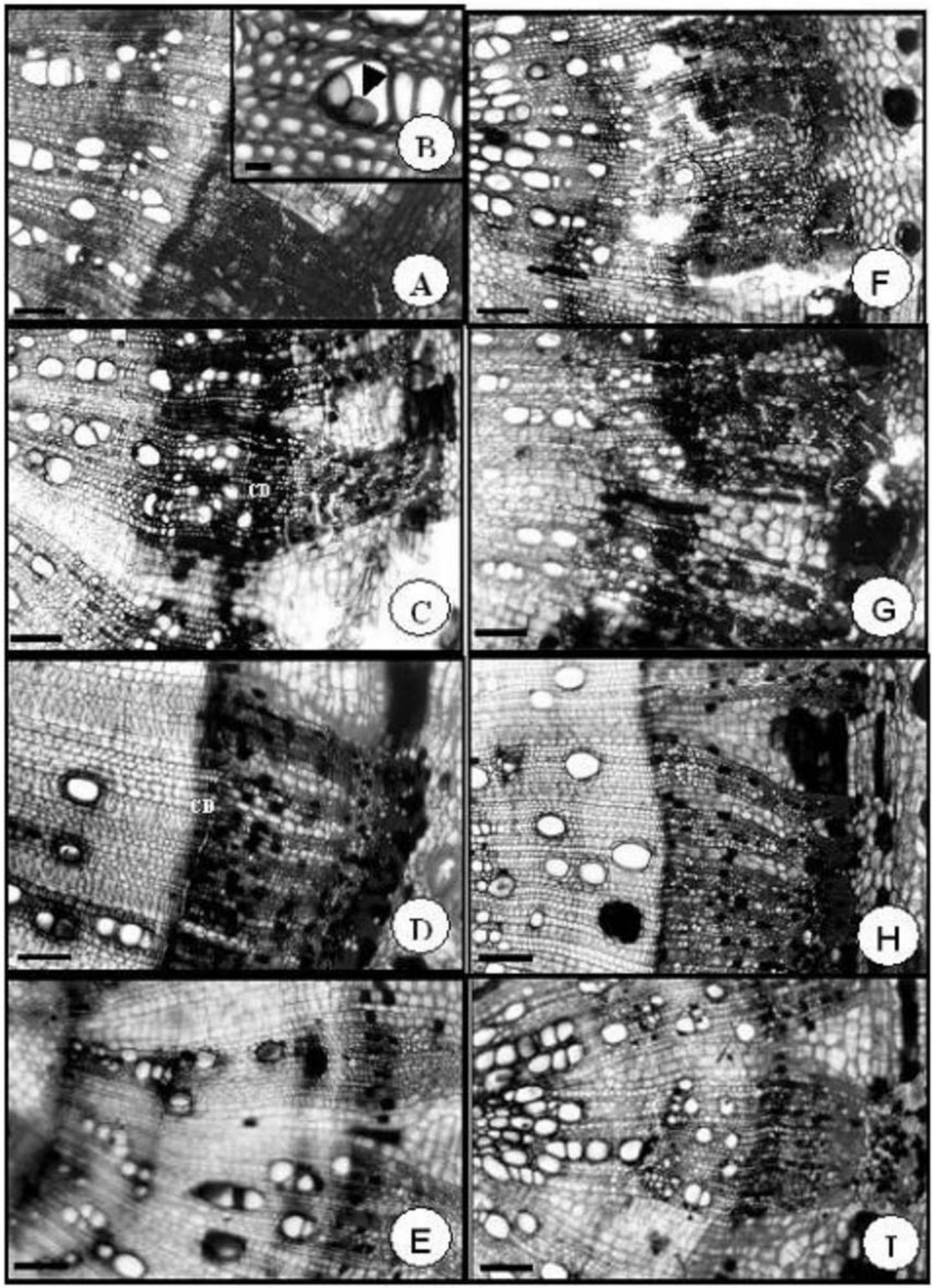

FIGURA 8 - Secção transversal do caule de T. cacao dos clones PS-1319, CA-1.4, CCN-10 e CP-53, A, B, C e D, respectivamente, para o controle e E, F, G e H para o tratamento $4 \mathrm{~g} \mathrm{~kg}^{-1}$ de AIB, 160 dias após a aplicação de ácido indol-3-butírico (AIB). Barra $=60 \mu \mathrm{m} .1 \mathrm{e} 2$, detalhe da tilose. As setas indicam fibras agrupadas. Barra $=60 \mu \mathrm{m}$. 


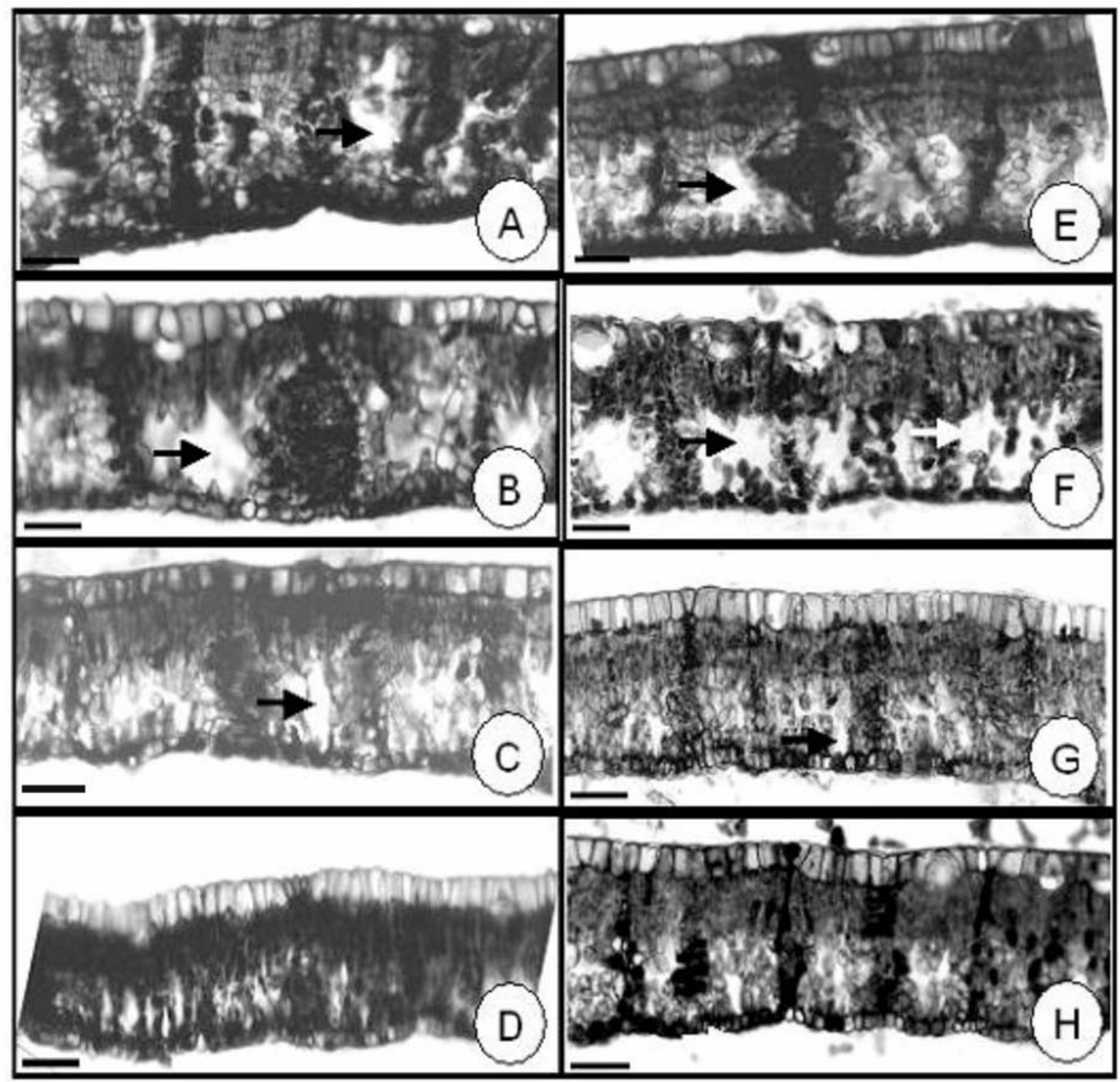

FIGURA 9 - Secção transversal da folha de T. cacao dos clones PS-1319, CA-1.4, CCN-10 e CP-53, A, B, C e D, respectivamente, para o controle e E, F, G e H para o tratamento $4 \mathrm{~g} \mathrm{~kg}^{-1}$ de AIB, 160 dias após a aplicação de ácido indol-3-butírico (AIB). As setas indicam espaço intercelular na região do parênquima lacunoso. Barra $=30 \mu \mathrm{m}$.

\section{CONCLUSÕES}

1-Houve respostas diferenciais dos clones de T. cacao (CCN-10, CP-53, PS-1319 e CA-1.4) às variações das concentrações de AIB na sobrevivência das estacas de caule, na indução da formação de raízes adventícias e na produção de biomassa seca das mudas clonais.

2-Concentrações crescentes de AIB, durante o enraizamento das estacas de caule, proporcionaram incremento de biomassa seca nos órgãos vegetativos dos clones CP-53 e PS-1319 até $4 \mathrm{~g} \mathrm{~kg}^{-1}$ de AIB e dos clones CCN-10 e CA-1.4 até 6 e $8 \mathrm{~g} \mathrm{~kg}^{-1}$ de AIB, respectivamente, e diminuição da mortalidade das estacas para os clones CA-1.4 e CCN-10 até $8 \mathrm{~g} \mathrm{~kg}^{-1}$ de AIB e CP-53 até $4 \mathrm{~g} \mathrm{~kg}^{-1}$ de AIB e aumento para o clone PS-1319.
3-A variação das concentrações de AIB promoveu mudanças anatômicas nos órgãos das mudas dos diversos clones de $T$. cacao avaliados, influenciando principalmente a atividade do câmbio vascular na estaca.

4-As melhores concentrações de AIB para o enraizamento de estacas de ramos dos clones de cacaueiros CP-53, PS-1319 e CCN-10 foram de 4, 4 e $6 \mathrm{~g} \mathrm{~kg}^{-1}$ de AIB, respectivamente, enquanto que para o clone CA-1.4 foi de $8 \mathrm{~g} \mathrm{~kg}^{-1}$ de AIB. 


\section{REFERÊNCIAS}

ALMEIDA, A-A.F.; VALLE, R.R. Ecophysiology of the cacao tree. Brazilian Journal of Plant Physiology, Brasília, v.19, n. 4, p. 425-448, 2007.

AZAMAL, H.; MOHINDER, P. Variation in shoot anatomy and rooting behaviour of stem cuttings in relation to age of donor plants in teak (Tectona grandis Linn. f.). New Forests, Dordrecht, v.31, n.1. p.57-73, 2006.

BASTOS, D.C.; PIO, R.; SCARPARE FILHO, R.J.A.; LIBARDI, M.N.; ALMEIDA, L.F.P.; ENTELMANN, F.A. Enraizamento de estacas lenhosas e herbáceas de cultivares de caquizeiro com diferentes concentrações de ácido indolbutírico. Revista Brasileira de Fruticultura. Jaboticabal, v.27, n.1, p.182-184, 2005.

BERTOLDE, F.Z. Respostas fisiológicas ao alagamento do substrato e diversidade genética molecular de clones de Theobroma cacao L. 2007. 89 f. Dissertação (Mestrado em Genética e Biologia Molecular) - Universidade Estadual de Santa Cruz, Ilhéus, 2007.

COSTA JR, W.H.; SCARPARE FILHO, J.A.; BASTOS, D.C. Estiolamento da planta matriz e uso de ácido indolbutírico no enraizamento de estacas de goiabeiras. Revista Brasileira de Fruticultura, Jaboticabal, v.25, n.2, p.301-304, 2003.

COUTINHO, E.F.; MIELKE, M.S.; ROCHA, M.S.; DUARTE, O.R. Enraizamento de estacas semilenhosas de frutíferas nativas da família Myrtaceae com o uso do ácido-indolbutírico. In: CONGRESSO BRASILEIRODEFRUTICULTURA, 11, Petrolina; PE, 1991. Revista Brasileira de Fruticultura, Jaboticabal, v.13, n.1, p.168-171, 1991.

DAVIS, T.D.; HAISSIG, B.E. Biology of adventitious root formation. New York: Plenum Press, 1994. p 364.

DIAS, L.A.S. Propagação vegetativa vs reprodução seminal em cacau. In: REUNIÃO ANUAL DA SOCIEDADE BRASILEIRA PARA O PROGRESSO DA CIÊNCIA, 45., 1993. Recife. Anais... Recife: SBPC, 1993. v.1.

FARIA, J.C.; SACRAMENTO, C.K. Enraizamento e crescimento de estacas herbáceas do cacaueiro (clones CEPEC 42, TSH 516 E TSH 1188) em função da aplicação do AIB. Revista Brasileira de Fruticultura. Jaboticabal, v.25, n.1, p.192-194, 2003.

GONTIJO, T.C.A.; RAMOS, J.D.; MENDONÇA, V.; PIO, R.; ARAÚJO NETO, S.E.; CORRÊA, F.L.O. Enraizamento de diferentes tipos de estacas de aceroleira utilizando ácido indolbutírico. Revista Brasileira de Fruticultura. Jaboticabal, v.25, n.2, p.290-292, 2003.

GUILTINAN M. J.; MILLER, C.R.; TRAORE, A.; MAXIMOVA, S.N. Greenhouse and field evaluation of orthotropic cocoa plants produced via somatic embryogenesis, micro and macropropagation. In: INTERNATIONALCOCOA RESEARCH CONFERENCE, 13., 2000, 9-14 outubro, Kota Kinabalu. Proceedings... Lagos, NGA: COPAL, 2000. p.276-501.

HARTMANN, H.T.; KERSTER, D.E.; DAVIES JR., F.T.; GENEVE, R.L. Plant propagation: principles and practices. $6^{\text {th }}$ ed. New Jersey: Prentice-Hall, 1997. p.276-501.

IRITANI, C.; SOARES, R.V.; GOMES, A.V. Aspectos morfológicos da aplicação de reguladores de crescimento nas estacas de Ilex paraguariensis St. Hilaire. Acta Biológica Paranaense, Curitiba, v.15, p.21-45, 1986 .

JOHANSEN, D. Plant microtechnique. New York: Mc Graw-Hill Bood, 1940. 450p.

KRAUS, J.E.; ARDUIN, M. Manual básico de métodos em morfologia vegetal. Seropédica: Editora da Universidade Federal Rural do Rio de Janeiro, 1997. v.1, 198p.

LASKOWSKI, L.; BAUTISTA, D. Características anatómicas de raíces adventicias en estacas de semeruco (Malpighia emarginata DC) tratadas con ácido indolbutírico. Bioagro, Barquisimeto, v.11, n.3, p. 88-96, 1999.

LAWES, G.S.; SIM, B.L. An Analysis of factors affecting the propagation of kiwifruit. Orchardist of New Zealand, Wellington, v.53, n.3, p.88-90, 1980.

LEAKEY, R.R.B.; COUTTS, M.P. The dynamics of rooting in Triplochiton scleroxylon cutting their relation to leaf area, node position, dry weight accumulation, leaf water potentialand carbohydrate composition. Tree Physiology, Victoria, v.5, p.135$146,1989$.

LEITE, J.B.V. Cacaueiro: Propagação por estacas caulinares e plantio no semi-árido do estado da Bahia. 2006. $84 \mathrm{f}$. Tese (Doutorado em Produção Vegetal) - Faculdade de Ciências Agrárias e Veterinárias, Universidade Estadual Paulista, Jaboticabal, 2006.

LIMA, R.L.S.; SIQUEIRA, D.L.; WEBER, O.B.; CAZETTA, J.O. Comprimento de estacas e parte do ramo na formação de mudas de aceroleira. Revista Brasileira de Fruticultura, Jaboticabal, v.28, n.1, p.83-86, 2006.

LIONAKIS, S.M. Anatomy of root initiation in stem cuttings of kiwifruit plant (Actinidia chinenses PLANCH.). Fruits, Paris, v.39, n.3, p.207-210, 1984.

LOPES, J.C. ALEXANDRE, R.S.; SILVA, A.E. C.; RIVA, E.M. Influência do ácido indol-3-butírico e do substrato no enraizamento de estacas de acerola. Revista Brasileira de Agrociência, Pelotas, v.9, n.1, p.79-83, 2003. 
MACHADO, M.P.; MAYER, J.L.S.; RITTER, M.; BIASI, L.A. Ácido indolbutírico no enraizamento de estacas semilenhosas do porta-enxerto de videira 'VR 043-43' (Vitis vinifera x Vitis rotundifolia). Revista Brasileira de Fruticultura, Jaboticabal, v.27, n.3, p.476-479, 2005.

MANFROI, V.; FRANCISCONE, A.H.D.; BARRADAS, C.I.N.; SEIBERT, E. Efeito do AIB sobre o enraizamento e desenvolvimento de estacas de Quiui (Actinidia deliciosa). Ciência Rural, Santa Maria, v.27, n.1, p.43-45, 1997.

MARROCOS, P.C.L.; SODRÉ, G.A. Sistema de Produção de mudas de cacaueiros. In: BARBOSA, J.G.; PRIETO MARTINEZ, H, E; PEDROSA, M.W.; SEDIYAMA, M.A.N. (Ed.). Nutrição e adubação de plantas cultivadas em substrato. Viçosa: Universidade Federal de Viçosa, 2004. p.283-311.

MAYER, J.L.S.; BIASI, L.A.; BONNA, C. Capacidade de enraizamento de estacas de quatro cultivares de Vitis L. (Vitaceae) relacionadas com os aspectos anatômicos. Acta Botânica Brasílica, São Paulo, v.20, n.3, p.563-568. 2006.

MILLER, C.R.; GUILTINAN, M.J. Perspectives on rapid vegetative multiplication for orthotropic Scion and rootstock varieties of cocoa. In: INTERNATIONAL WORKSHOP ON COCOA BREEDING FORM IMPROVED PRODUCTION SYSTEMS, 2003, Accra. Proceedings... p.189-194, 2003.

NACHTIGAL, J.C. Propagação de araçazeiro (Psidium cattleyanum Sabine) através de estacas semilenhosas. Pelotas. 1994. 73 f. Dissertação (Mestrado) - Faculdade de Agronomia Eliseu Maciel, Universidade Federal de Pelotas, Pelotas, 1994.

NORBERTO, P.M.; CHALFUN, N.N.J.; PASQUAL, M.; VEIGA, R.D.; PEREIRA, G.E.; MOTA, J.H.. Efeito da época de estaquia e do AIB no enraizamento de estacas de figueira (Fícus carica L.). Ciência Agrotécnica, Lavras, v.25, n.3, p.533-541, 2001.
OLIVEIRA, A.F. PASQUAL, M.; CHALFUN, N.N.J.; REGINA, M.DEA.; RINCÓN, C.D.R. Enraizamento de estacas semilenhosas de Oliveira sob efeito de diferentes épocas, substratos e concentrações de ácido indolbutírico. Ciência Agrotécnica, Lavras, v.27, n.1, p.117-125, 2003.

PEREIRA, J.L.; RAM, A.; FIGUEIREDO, J.M.; ALMEIDA, L.C.C. Primeira ocorrência de vassoura-de-bruxa na principal região produtora de cacau do Brasil. Agrotrópica, Ilhéus, v.1, n.1, p.7981, 1989.

SCHWARZ, J.L.; GLOCKE, P.L. \& SEDGLEY, M. Adventitious root formation in Acacia baileyana F. Muell. Journal of Horticultural Science \& Biotechnology, United Kingdom, v. 74, n.5, p.561-565, 1999.

SENA-GOMES, A.R.; CASTRO, G.C.; MORENO-RUIZ, M.M.; ALMEIDA, H.A. Avanços na propagação clonal do cacaueiro no Sudeste da Bahia. In: PEREIRA, J.L.; SERÓDIO, M.H.; BEZERRA, J.L. (Ed.). Atualização sobre produção massal de propágulos de cacau geneticamente melhorados. Ilhéus: Atas, 2000. p.85-89, 2000.

SODRÉ, G.A. Efeito do comprimento da miniestaca no crescimento de mudas de cacaueiro, pp 44-54. In: Substratos e estaquia na produção de mudas de cacaueiro. 2007. $84 \mathrm{f}$. Tese (Doutorado em Produção Vegetal) - Faculdade de Ciências Agrárias e Veterinárias, Universidade Estadual Paulista, Jaboticabal, 2007.

TAIZ, L.; ZEIGER, E. Fisiologia vegetal. 3. ed. Porto Alegre: Artmed Editora, 2004. 719 p.

WENDLING, I.; XAVIER, A. Influência do ácido indolbutírico e da miniestaquia seriada no enraizamento e vigor de miniestacas de clones de Eucaliptus grandis. Revista Árvore, Viçosa, v.29, n.6, p.921-930, 2005.

WENDLING, I.; XAVIER, A.; GOMES, J.M.; PIRES, I.E.; ANDRADE, H.B. Propagação clonal de híbridos de Eucalyptus spp. por miniestaquia. Revista Árvore, Viçosa, v.2, n.2, p.181$186,2000$. 